\title{
Induced sputum for the diagnosis of pulmonary tuberculosis: Is it useful in clinical practice?
}

\author{
S-R Olsen MD FRCPC ${ }^{1}$, R Long MD FRCPC ${ }^{1}$, GJ Tyrrell PhD FCCM ${ }^{2}$, D Kunimoto MD FRCPC ${ }^{3}$
}

\author{
S-R Olsen, R Long, GJ Tyrrell, D Kunimoto. Induced sputum for \\ the diagnosis of pulmonary tuberculosis: Is it useful in clinical \\ practice? Can Respir J 2010;17(4):e81-e84.
}

BACKGROUND: Diagnosing pulmonary tuberculosis (PTB) is challenging in patients who are unable to spontaneously expectorate. Published evidence suggests that induced sputum (IS) is the least invasive and most cost-effective method of diagnosis, and should be used before fibre-optic bronchoscopy (FOB).

METHODS: The medical records of 337 adults treated for PTB in northern Alberta between 1997 and 2007 were reviewed to determine whether local practice patterns reflect the evidence. Microbiological data were collected from the Provincial Laboratory for Public Health. Demographic information was collected from the patients' charts.

RESULTS: A total of $8.5 \%$ (26 of 307) of PTB patients had IS collected, whereas $35.8 \%$ (110 of 307) underwent FOB. Among FOB patients, 56.4\% (62 of 110) had no sputum sent before the procedure and 29\% (18 of 62) of these patients were smear positive. Only five patients referred for FOB had IS sent previously. There were no demographic factors predictive of IS use, whereas being an inpatient at a teaching facility or having a nodule or mass on chest $\mathrm{x}$-ray was predictive of FOB referral. Because so few IS samples were available, not all patients had spontaneously expectorated sputum, IS and FOB tests performed; thus, the calculated yields were not comparable with one another.

CONCLUSIONS: Despite published evidence recommending IS collection before FOB referral in suspected PTB patients, clinicians in our health region appeared to prefer early FOB over IS by a large margin. This practice pattern is less cost effective and exposes patients and health care workers to greater risk. Further research is needed to identify the reasons for the underuse of sputum induction.

Key Words: Bronchoscopy; Diagnosis; Induced sputum; Tuberculosis

A vailable methods for obtaining microbiological confirmation of active pulmonary tuberculosis (PTB) include the examination of spontaneously expectorated sputum (SES), induced sputum (IS), gastric washings, aspirates from fibreoptic bronchoscopy (FOB) and collection of postbronchoscopy sputum. In patients unable to spontaneously expectorate, published evidence suggests that IS is an effective, noninvasive and cost-efficient method of diagnosis (1-6), and that it should be used before FOB referral (7).

FOB increases the potential for patient complications including bleeding, airway complications and pneumothorax, whereas IS has fewer potential side effects (8). FOB also puts health care workers at increased risk of contracting PTB (9-11).

The sixth edition of the Canadian Tuberculosis Standards, recommends that FOB be used only if IS and SES are unavailable, or if all samples are smear negative (7).

\author{
Induction des expectorations pour le diagnostic de \\ la tuberculose pulmonaire : Est-ce utile dans la \\ pratique clinique?
}

HISTORIQUE : Le diagnostic de la tuberculose pulmonaire (TBP) est un défi chez les patients qui sont incapables d'expectorer spontanément. Les preuves publiées donnent à penser que l'induction des expectorations (IE) est la méthode diagnostique la moins effractive et la plus économique et elle doit être utilisée avant la bronchoscopie par fibre optique (BFO).

MÉTHODES : On a passé en revue les dossiers médicaux de 337 adultes traités pour TBP dans le Nord de l'Alberta entre 1999 et 2007 afin de déterminer si les modes de pratique locaux sont le reflet des récentes directives. Les données microbiologiques ont été recueillies à partir du laboratoire provincial de santé publique. Quant aux renseignements démographiques, ils ont été recueillis à partir des dossiers des patients.

RÉSULTATS : En tout, on a soumis $8,5 \%$ des patients atteints de TBP (26 sur 307) à l'IE, tandis que 35,8 \% (110 sur 307) ont subi une BFO. Parmi les patients soumis à la $\mathrm{BFO}, 56,4 \%$ (62 sur 110) n'avaient soumis aucun spécimen d'expectoration avant l'intervention et $29 \%$ (18 sur 62) de ces patients présentaient un frottis positif. Seulement cinq patients soumis à la $\mathrm{BFO}$ avaient déjà fourni un spécimen par IE. Aucun facteur démographique n'a semblé prédicteur de l'utilisation de l'IE, tandis que le fait d'être hospitalisé dans un établissement d'enseignement ou de présenter un nodule ou une masse à la radiographie pulmonaire était prédicteur d'une demande de BFO. Étant donné le si petit nombre d'échantillons d'IE accessibles, les patients n'ont pas tous subi de tests sur des expectorations spontanées, des expectorations induites et des spécimens de BFO; ainsi, les rendements calculés n'ont pu être comparés les uns aux autres.

CONCLUSIONS : Malgré les preuves publiées recommandant l'IE avant toute demande de BFO chez les patients soupçonnés de souffrir de TBP, un important pourcentage de médecins de notre régie régionale ont semblé préférer une BFO précoce plutôt que l'IE. Cette pratique est moins économique et expose les patients et les travailleurs de la santé à un risque plus grand. Il faudra approfondir la recherche pour découvrir les raisons de la sousutilisation de l'induction des expectorations. 
TABLE 1

\section{Patient characteristics}

\begin{tabular}{lc}
\hline Mean age, years (range) & $53.6(18-96)$ \\
Sex & \\
Male & $181(59)$ \\
Female & $126(41)$ \\
Site of diagnosis & \\
Outpatients & $149(48.5)$ \\
Inpatients & $124(40.4)$ \\
Not available & $34(11.1)$ \\
HIV serostatus & \\
Patients tested & $233(76)$ \\
HIV positive & $17(5.5)$ \\
Chest x-ray & \\
Report available & $290(94)$ \\
Active disease, $\mathrm{n} / \mathrm{n}(\%)$ & $194 / 290(66)$ \\
Inactive & \\
Nodule/mass, $\mathrm{n} / \mathrm{n}(\%)$ & $96 / 290(33)$ \\
\hline
\end{tabular}

Data presented as $n$ (\%) unless indicated otherwise. *Inactive disease as defined by Canadian Tuberculosis Standards, 6th edition (see methods)

TABLE 2

Results according to method of diagnosis

\begin{tabular}{|c|c|c|c|c|c|}
\hline & Patients & $\begin{array}{c}\text { Smear } \\
\text { positive, } \\
\text { culture } \\
\text { negative }\end{array}$ & $\begin{array}{c}\text { Smear } \\
\text { negative, } \\
\text { culture } \\
\text { positive }\end{array}$ & $\begin{array}{c}\text { Smear } \\
\text { negative, } \\
\text { culture } \\
\text { negative }\end{array}$ & $\begin{array}{l}\text { Sensitivity } \\
\%\end{array}$ \\
\hline Total* & 307 & 148 & 198 & 88 & \\
\hline SES & 272 & 111 & 121 & 40 & 85.3 \\
\hline Induced sputum & 26 & 4 & 11 & 11 & 57.7 \\
\hline $\begin{array}{l}\text { Fibre-optic } \\
\text { bronchoscopy }\end{array}$ & 110 & 23 & 55 & 32 & 70.7 \\
\hline $\begin{array}{l}\text { Postbronchoscopy } \\
\text { sputum }\end{array}$ & 26 & 10 & 11 & 5 & 80.8 \\
\hline
\end{tabular}

Data presented as $n$ unless indicated otherwise. *Total number of samples exceeds number of patients because some patients submitted more than one sample type. SES Spontaneously expectorated sputum

Alberta). Using the local PTB registry, 337 adults treated for PTB in northern Alberta between 1997 and 2007 were identified. Pediatric cases were excluded because the indications for sputum induction are not as well established in children. Microbiological data were collected from the Provincial Laboratory for Public Health, where all mycobacteriology testing in the province is performed. The results of all diagnostic samples sent before the date that antituberculous medications were initiated were recorded, as were the sampling method and the smear and culture results. Postbronchoscopy sputum samples were considered as such if sent within $48 \mathrm{~h}$ following the procedure. The hospital or other clinical setting of collection was also recorded. Demographic information was collected from the patients' charts including age, sex, HIV status and chest $\mathrm{x}$-ray (CXR) results as reported by a radiologist. CXR reports were considered 'inactive' if they were reported to be normal or if they had findings consistent with previous tuberculosis as outlined in the sixth edition of the Canadian Tuberculosis Standards (granulomas, calcified hilar nodes, costophrenic angle blunting, apical pleural capping or apical fibronodular disease) (8). Statistical analysis was performed using the two-tailed $t$ test or $\chi^{2}$ test, as indicated.

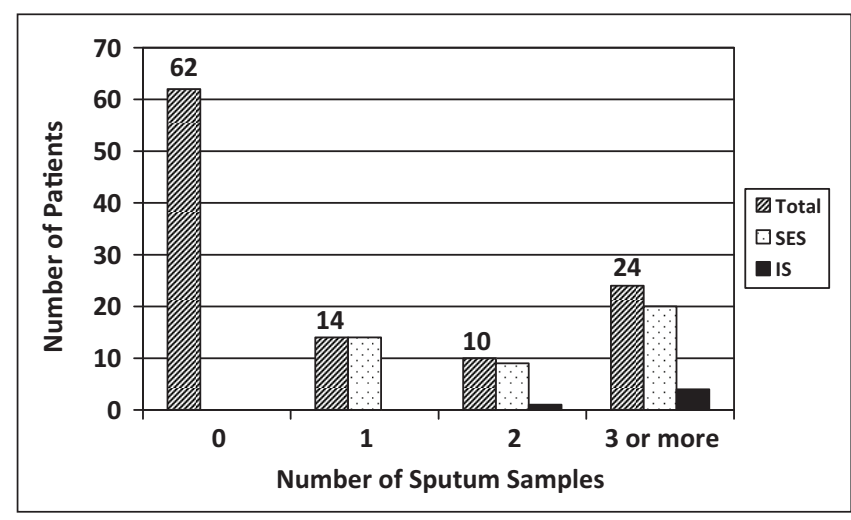

Figure 1) Number of sputum samples sent before bronchoscopy referral. Most patients (62 of 110) referred for bronchoscopy did not have sputum samples, either spontaneously expectorated (SES) or induced (IS) sputum sent before the procedure. Only five of 110 patients had IS ordered before bronchoscopy

\section{Patient characteristics}

\section{RESULTS}

Of the 337 patients identified, 30 were excluded because of inadequate data. Of the 307 remaining patients, 41 had no positive microbiological confirmation of PTB and were treated on the basis of clinical suspicion; these patients were included in the final analysis. Patient characteristics are summarized in Table 1.

\section{Use of SES samples}

A total of 272 patients had at least one SES sample sent before starting treatment, while 111 patients had at least one smearpositive sputum sample. An additional 121 patients had at least one smear-negative/culture-positive sputum sample, yielding an overall sensitivity of $85.3 \%$ in the group of patients with SES sent (Table 2). A total of 179 patients (77.2\%) had a positive smear or culture on the first SES sample sent, yielding a sensitivity of $65.5 \%$ for a single sputum sample.

\section{Use of IS samples}

Only $8.5 \%$ (26 of 307 ) of patients had one or more IS samples ordered. Twenty-two of the 26 IS samples were sent after 2002. Of the 26 samples sent, 15 were either smear or culture positive, yielding a sensitivity of $57.7 \%$ in this group (Table 2).

\section{Use of bronchoscopy}

A total of $35.8 \%$ (110 of 307) of patients were referred for FOB. Of these patients, 78 were either smear or culture positive, yielding a sensitivity of $70.7 \%$ in this group (Table 2 ). In the group of patients who underwent FOB, 56.4\% (62 of 110) did not have a sputum sample of any kind sent before the procedure (Figure 1). Twenty-nine per cent (18 of 62) of these patients were smear positive at bronchoscopy. Only 0.5\% (five of 110) of patients referred for FOB had IS sent before the procedure (Figure 1).

Use of postbronchoscopy sputum samples

A total of 26 patients had a postbronchoscopy sputum sample sent. Of these, 10 were smear positive and 11 were smear negative/culture positive, for an overall sensitivity of $80.8 \%$ (Table 2). Of note, seven patients with a positive postbronchoscopy sputum sample had culture-negative samples at bronchoscopy. 


\section{Secondary outcomes}

No demographic factors that were predictive of IS use were found. The majority of the IS samples were obtained from outpatients (18 of 26), with only eight samples collected from inpatients; however, this difference did not reach statistical significance. A difference in practice pattern between the three teaching hospitals in the city - one of which is primarily a community practice, one is university affiliated and the other is located in the downtown core - was anticipated. A total of 63, 26 and 71 PTB patients were diagnosed at each hospital respectively; however, the rate of IS use between sites was not significantly different at $11.5 \%$ (three of 63 ), $3.8 \%$ (one of 26 ) and $26.9 \%$ (seven of 71 ), respectively. The remaining 15 IS samples were sent from a variety of sites other than the three teaching hospitals; however, there was no significant difference in the rates of IS use between teaching and nonteaching sites. We also considered that CXR findings that were indicative of active PTB may have influenced the rate of IS submission, but this was not the case because 12 of 26 IS samples were from patients with an active CXR versus 11 of 26 from those with a reportedly 'inactive' CXR. Because none of the IS samples belonging to HIV-positive patients were sent, this factor could not be evaluated. Age and sex were not predictive of IS use.

In contrast, it was found that FOB was more likely to be performed on inpatients (56 of 124) than outpatients (39 of 149 ) - a finding that was statistically significant $(P=0.001)$. Seventy-six of 110 FOB patients had a CXR consistent with active PTB versus only 29 with a reportedly inactive CXR, but this difference did not reach statistical significance. Twenty of 110 FOB patients had a nodule or mass on CXR (other than a granuloma) - a finding that was statistically significant $(\mathrm{P}=0.014)$. There was no difference in $\mathrm{FOB}$ referral among hospital sites, with rates of FOB referral of $50.8 \%$ (32 of 63 ), $53.8 \%$ (14 of 26 ) and $50.7 \%$ (36 of 71 ), respectively. The remaining $28 \mathrm{FOB}$ samples were collected from sites other than the three main teaching hospitals, yielding a rate of $19 \%$ (28 of 119), which was significantly different than the rate at teaching sites $\left(\mathrm{P}=4.14 \times 10^{-9}\right)$. Other demographic factors including HIV serostatus, sex and age were not predictive of bronchoscopy referral.

\section{DISCUSSION}

The primary purpose of the present study was to evaluate the practice pattern of diagnosing PTB in our health region, which has a well-resourced tuberculosis control program and ready access to tuberculosis specialist physicians. The sixth edition of the Canadian Tuberculosis Standards recommends that when SES is not diagnostic or cannot be obtained, sputum induction is preferred over FOB as the method of diagnosis (7). The current study demonstrated that surprisingly few PTB patients in our health region underwent IS testing, suggesting that clinicians prefer early FOB over IS by a large margin. Only $8.5 \%$ (26 of 307 ) of PTB patients had IS ordered, whereas $35.8 \%$ (110 of 307) had FOB. One might expect FOB to be performed if several IS samples were obtained and found to be smear negative; however, only five patients $(0.5 \%)$ had IS ordered before bronchoscopy referral (Figure 1).

We believe that these results have several key implications for patient care in our health region and across the country. First, the cost of IS has been shown to be substantially less than
FOB $(1,2)$ and, although Canada would be considered to be a resource-rich country worldwide, the success and sustainability of our health care system depends on intelligent stewardship of all resources. The present study showed that physicians in our health region were opting for the more expensive route.

Cost aside, the primary consideration for clinicians is the patient's well-being. In this regard, there is ample evidence proving the effectiveness of IS for diagnosing PTB. A 1995 study by Anderson et al (1) that compared IS with FOB found that sputum induction had a sensitivity of $87 \%$ while bronchoscopy had a sensitivity of $73 \%$. These results were supported in several more recent trials. In a study from New Zealand from 2000, McWilliams et al (2) diagnosed 41 of 42 (98\%) cases of PTB after three IS samples were taken with only one additional case detected by FOB. In 2007, Brown et al (3) demonstrated that performing $\mathrm{FOB}$ on 21 patients who had smear-negative results by IS did not yield any additional positive cultures. A prospective study by Schoch et al (4), also from 2007, evaluated the use of IS in immigrants to Switzerland with suspicious chest radiographs who were unable to expectorate spontaneously. They discovered that using IS in addition to SES increased the yield of culture-positive PTB from $60 \%$ to greater than $80 \%$. Performing FOB added four smear-positive and six culture-positive cases; however, the examination of bronchial aspirates alone would have missed nine of 33 (27\%) cases (4). A 2008 prospective comparison (5) of IS and FOB for the diagnosis of suspected smear-negative PTB cases in Bangladesh found that IS had a significantly higher diagnostic yield (74\%) than FOB (58\%). A 2009 study by Bell et al (6) found that 44 of $46(95.6 \%)$ cases of PTB were detected by SES or IS, with limited additional diagnostic yield provided by FOB.

The clinician may be tempted to assume that because FOB is more invasive than IS, it will be more 'definitive'. The above evidence proves that this is not the case and, in fact, the patient is exposed to additional risk from the more invasive procedure (8). A recent review article by Mohan and Sharma (12) on the diagnosis of smear-negative PTB suggested that early FOB referral may be the preferred diagnostic modality (over IS) in resource-rich environments. We would argue that patients in all countries should benefit from noninvasive diagnostic techniques, such as sputum induction, before being subjected to procedures with more potential for complications.

A concerning finding in our study was that $54.5 \%$ of patients underwent FOB with no previous sputum samples sent and that $29 \%$ of these patients were smear positive at bronchoscopy. There is evidence to suggest that FOB increases the transmission of PTB to health care workers (9-11); thus, sending smear-positive patients to the bronchoscopy suite may pose significant risks to bronchoscopy attendees, which often include students and residents in addition to the regular bronchoscopy suite staff at our teaching hospitals.

Based solely on our data, it is difficult to draw conclusions as to why FOB was preferred over IS in our health region. Our study was retrospective in nature, with data that were collected from microbiology test results; therefore, we cannot speculate on the clinician's rationale for ordering tests in each specific case. However, we attempted to correlate FOB referral with demographic factors collected from the patients' charts. We found that patients with a mass or nodule on CXR other than a 
granuloma was predictive of referral for FOB. This is logical because such a finding would imply a possible malignancy and may prompt the clinician to order FOB rather than IS. More inpatients underwent FOB than outpatients and we can only speculate as to the reason for this. It may suggest that a more invasive procedure is preferred for patients with greater disease severity such as hospital inpatients or because of a lack of access to inpatient sputum induction equipment. Patients at the three teaching hospitals were more likely to undergo FOB than those diagnosed in a nonteaching environment - this almost certainly reflects the fact that many smaller facilities in our health region do not have bronchoscopic capabilities and are referring their patients to the teaching hospitals for the procedure.

One of the secondary goals of our study was to determine the yield of the various diagnostic methods in our health region. Unfortunately, several limitations of the present study prevented us from drawing any strong conclusions. Because there were too few IS samples available, not all patients had

\section{REFERENCES}

1. Anderson C, Inhaber N, Menzies RI. Comparison of sputum induction with fibre-optic bronchoscopy in the diagnosis of tuberculosis. Am J Respir Crit Care Med 1995;152:1570-4.

2. McWilliams T, Wells A, Lindstrom S, et al. Comparison of sensitivity of induced sputum with bronchoscopy for diagnosis of pulmonary tuberculosis. Am J Respir Crit Care Med 2000;161:A303.

3. Brown M,Varia H, Bassett P, et al. Prospective study of sputum induction, gastric washing and bronchoalveolar lavage for the diagnosis of pulmonary tuberculosis in patients who are unable to expectorate. Clin Infect Dis 2007;44:1415-20

4. Schoch OD, Rieder P, Tueller C, et al. Diagnostic yield of sputum, induced sputum, and bronchoscopy after radiologic tuberculosis screening. Am J Respir Crit Care Med 2007;175:80-6.

5. Ganguly KC, Hiron MM, Mridha ZU, et al. Comparison of sputum induction with broncho-alveolar lavage in the diagnosis of smear-negative pulmonary tuberculosis. Mymensingh Med J 2008; 17:115-23.

6. Bell DJ, Dacombe R, Graham SM, et al. Simple measures are as
SES, IS and FOB testing performed. Thus, the calculated yields (Table 2) are not comparable because they represent different patient groups.

\section{CONCLUSION}

The practice pattern in our health region for diagnosing PTB appears to favour the use of FOB over IS, despite published evidence indicating that IS is more cost efficient, less invasive and more effective at diagnosing PTB than FOB. Further research is needed to address the underlying reasons for this trend.

ACKNOWLEDGEMENTS: The authors thank TB Services, the Departments of Respiratory Therapy at the University of Alberta and Royal Alexandra Hospitals (Edmonton, Alberta) and the Provincial Laboratory for Public Health.

CONFLICTS OF INTEREST: None of the authors have conflicts of interest to declare.

effective as invasive techniques in the diagnosis of pulmonary tuberculosis in Malawi. Int J Tuberc Lung Dis 2009;13:99-104.

7. Canadian Tuberculosis Standards. 6th edn. The Canadian Lung Association and the Public Health Agency of Canada, 2007. <www.phac-aspc.gc.ca/tbpc-latb/pubs/tbstand07-eng.php> (Accessed on July 15, 2010).

8. Bell D, Leckie V, McKendrick, M. [Comment] Clin Infect Dis 2004;38:1504-5.

9. Malasky C, Jordan T, Potulski F, et al. Occupational tuberculosis infections among pulmonary physicians in training. Am Rev Respir Dis 1990;142:505-7.

10. Catanzaro A. Nosocomial tuberculosis. Am Rev Respir Dis 1982;125:559-62.

11. Beggs C, Noakes C, Sleigh P, et al. The transmission of tuberculosis in confined spaces: An analytical review of alternative epidemiological models. Int J Tuberc Lung Dis 2003; 7:1015-26.

12. Mohan A, Sharma SK. Fibre-optic bronchoscopy in the diagnosis of smear-negative tuberculosis: Current status. Indian J Chest Dis Allied Sci 2008;50:67-78. 


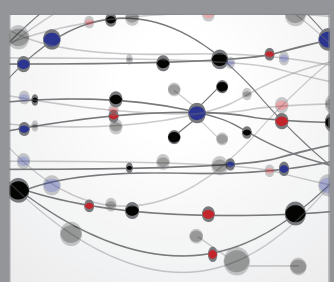

The Scientific World Journal
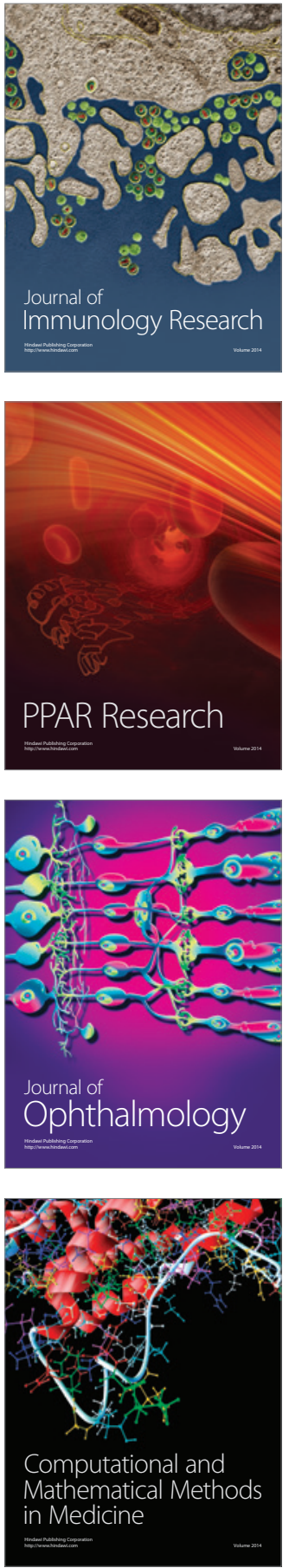

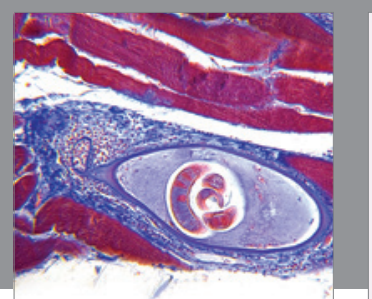

Gastroenterology Research and Practice

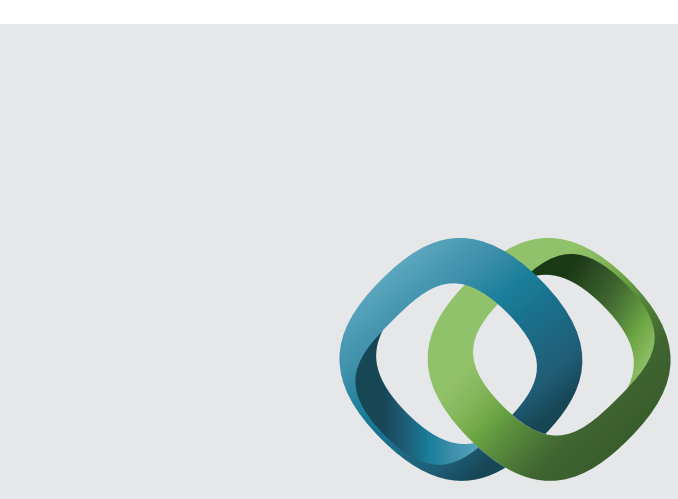

\section{Hindawi}

Submit your manuscripts at

http://www.hindawi.com
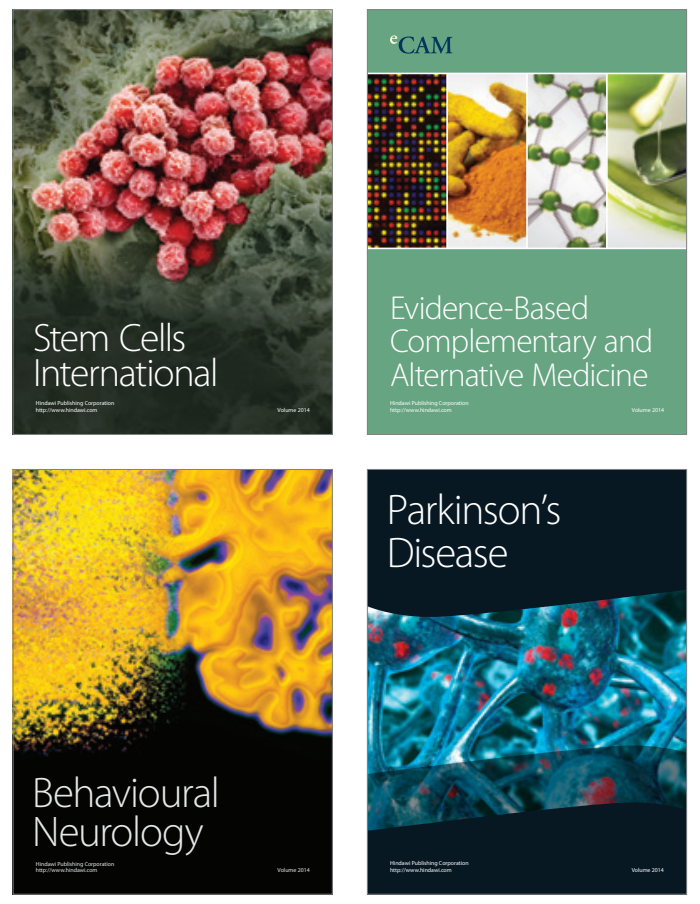
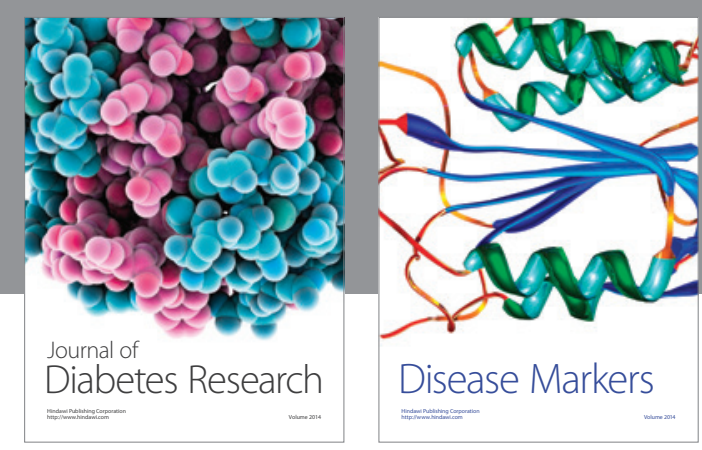

Disease Markers
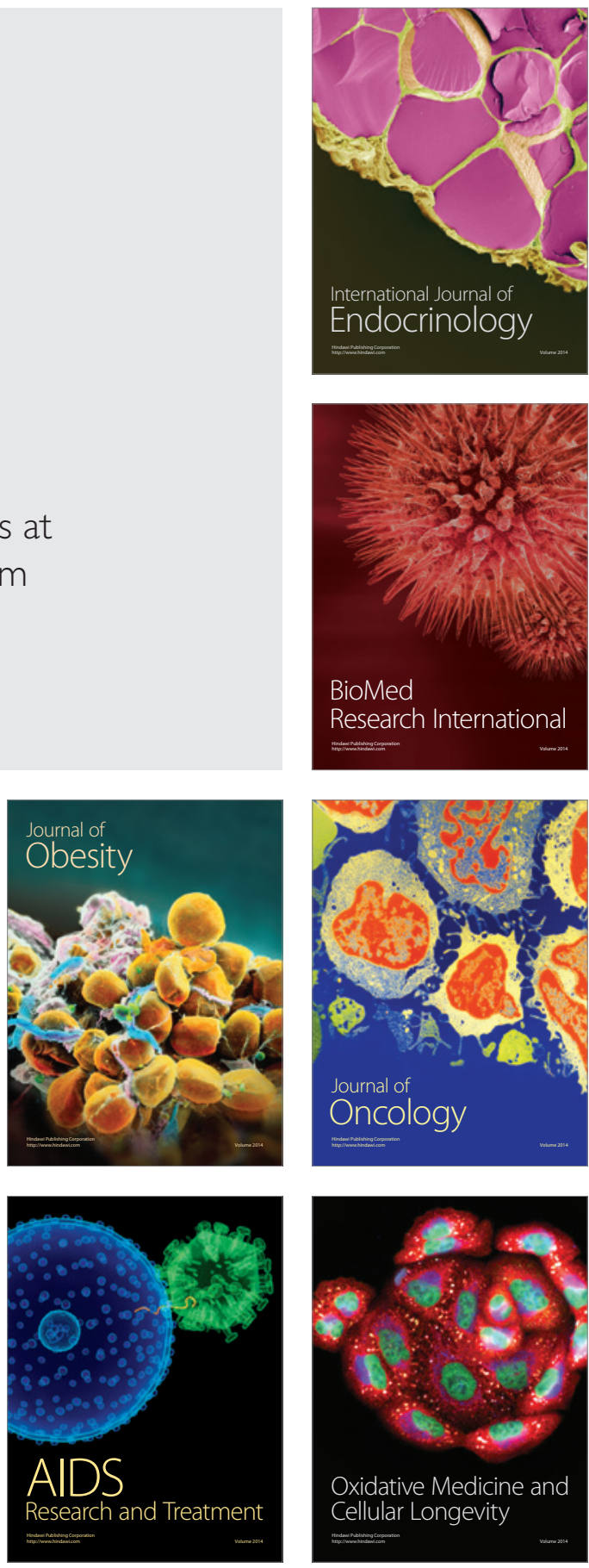